\title{
Reflections on Managing a Multinational Corporation in China: Business Model Innovations of the Internet Era
}

\author{
Zhang Ruimin, Haier Group, China
}

HAIER WAS FOUNDED IN 1984. In the last 30 years, through its entrepreneurial and innovative spirit, Haier has transformed itself from an insolvent collectively-owned factory on the brink of bankruptcy into the number one global home appliance brand. In 2014, Haier Group's global revenues reached US\$32.6 billion, while estimated profits grew three times faster than revenues - at 39 percent year-on-year - to US\$2.4 billion. Based on the statistics of Euromonitor International, a world leader in strategy research for consumer markets, Haier has been the number one global home appliance brand for six years in a row. In the 2012 World's 50 Most Innovative Companies list published by the Boston Consulting Group, Haier was the only Chinese company in the top 10, as well as the top-ranked consumer product retailer.

My topic for this reflection article is "business model innovations of the Internet era." Why this topic? Because I think the Internet age is a big challenge for all companies. If we failed to innovate in the Internet era, we would be left behind by this era.

I want to make three points. First, I will describe how successful companies move with the changing times. To survive, all companies must keep up with the times. Because things change too quickly, we must never stop challenging and conquering ourselves. Second, I will talk about what innovation efforts Haier has undertaken in the Internet era. Third, I will discuss a problem we haven't found a good solution to until this day. This is a very risky challenge to take on: it can help you reinvent yourself; but if not handled well, it might overturn you. I don't know how far our company has gone. Even though I'm very confident, this era is indeed very difficult to grasp.

\section{Successful Companies Move with the Changing Times}

A so-called successful company is one that has managed to stay in tune with the changing times. However, it is impossible to always keep in tune with the times because we are only human and not god. A company is like a surfer. Being able to rise to the top of a wave today does not guarantee that you will still stay on top of it tomorrow. For instance, in the cell phone industry, Motorola used to be number one. But it was soon surpassed by Nokia. The reason lies in the changing times. Motorola ruled the analog era, but Nokia seized the opportunity of the digital era. However, Nokia was soon surpassed by Apple as Apple was able to seize the opportunity of the Internet era. If you fail to move with the changing times, you will be phased out very quickly. This is especially true in the Internet era. I have a feeling that this age will bring about a total disruption.

The 200-year-old traditional management models are being smashed into pieces in the Internet era because their foundation is Adam Smith's division of labor theory, which explains how small workshops are transformed into modern corporations. This theory is also the root of theories by three pioneers of classical management thinkers: (1) Frederick Taylor's scientific management, which is the foundation of the assembly line, (2) the father of organization theory, Max Weber's, idea of bureaucracy, which still has currency today, (3) Henri Fayol's general management theory, which, in essence, is about applying various functions within a business to adapt to its external market.

With the arrival of the Internet era, I think all these theories have been overturned. Reason number one: zero distance. A business needs to be at zero distance to its customers. Therefore, production lines must be reformed to enable the transition from mass manufacturing to mass customization. Second, decentralization. In the Internet era, anyone can become a center, so there are really no centers nor leaders. Therefore, bureaucracy must be changed. Third, distributive management: I have access to resources from around the world. The entire world is my human resources department. As you can see, those general management theories are no longer relevant today. We are witnessing gigantic changes.

Greek philosopher Heraclitus said, "No man ever steps in the same river twice."This is because the river flows too quickly. The current era is like the incessant currents of a river. This is an important reason why Haier must change.

\section{Haier's Trial and Error in Business Model Innovation}

When Professor Meyer came to Haier 10 years ago and learned about the changes I was planning to implement, he said: if you managed to change this way, you would become an excellent global company, but I don't think you could, because of the sheer magnitude of the disruption it would cause. This is exactly why we haven't managed to change the way we wanted after so many years. Due to time constraints, I will address only three highlights in our ongoing experiments: (1) strategic shift, (2) organizational shift, (3) change in our remuneration system. 


\section{Strategy: Shifting to a Customer-Centric Win-Win Model of "Individual-Goal Combination"}

Companies used to be company-centric in the past. But in the Internet era, things have changed and we must put customers at the center. To adapt to the customer-centric reality, we adopted a strategy that we call "the win-win model of individual-goal combination." "Individual" refers to the employee; "goal" refers to customer resources. The strategy is about connecting each employee with their customer resources. "Win-win" refers to the fact that you prove your value by creating value for customers. What is so difficult about this multi-year effort to implement this strategy? The difficulty lies in how employees find their customers. Management guru Peter Drucker said that all companies must ask themselves a couple of questions, the first of which is: who is your customer? The second question is: what is the value that you remuneration. With these three powers, they managed to succeed. Some venture capitalists are investing in their project. We would like to see it become an entirely independent operation. Many other employees have started their own companies. We regularly hold Maker Fairs, an occasion for venture capitalists in the wider business community to evaluate new projects. This is how we are breaking down old organizational structure. Our philosophy is: "I create my customers and share the extra value that I create."When employees find their own customers and create value for them, they can share part of the value they created.

We believe that "the company is the people; the people are the company." Every entrepreneur can start their own business. This is a far cry from traditional management theory. In traditional management theory, there are three essential factors: the subject of management, the object of management, and the means of management. The subject of management is the manager. The object of management is the managed. The means of management is the models and tools used by the manager to manage the managed. This is a closed system. Now I'm turning it into an open system where everyone can start their own business and thereby overturning the old organization.

create for your customer? As one can well imagine, it is very hard to make each and every one of your employees find their own customers. We've been working at this for a long time.

We've overturned our old pyramid-shaped organizational structure, where employees at the bottom had many leaders above them and were unable to make their independent decisions. Now that they are liberated, they can find their customers and start an enterprise as long as they have their own ideas. Thus, employees at the bottom can go solo and start their own business.

For example, we have three young people in their twenties who discovered an opportunity in the gaming laptop segment. Many gaming laptop users are technology aficionados and have their own ideas about how gaming laptops should be built. These three young people found about 30,000 such ideas online and categorized them into 13 types of problems. To address these problems, they invented a new gaming laptop. All other resources are available in the wider business community: design, $R \& D$, manufacturing. As long as you have your customers, you can have other people make things for you. This gaming laptop, which is named ThundeRobot, is a product of resources integration from the wider business community. It started from scratch and is now among the best in its category.

What is it that empowered these three young people? First, the power to decide. Second, the power to hire. Third, the power to distribute

\section{Organization: Shifting to a Community of Interest That Maximizes Benefit for All Stakeholders}

The organizational structure used to be connected in series; now it is connected in parallel. Why this change? Business historian Alfred Chandler said it brilliantly: the growth of a business depends on two variables, strategy and organization. He also advanced the "structure follows strategy" thesis. Strategy follows and is designed for the changing era. The organization changes with the changing strategy. Now that our strategy has changed, the organization needs to change. In the past, the organization is connected in series: from planning, design, marketing, finally to the user. There are many gears between planning and the user. These gears do not know where the user is. They are the intermediaries within the company. There are also intermediaries in the wider business community. For example, suppliers and distributors are intermediaries that the company needs to deal with. Anyway, the company is far away from the user. Now we need to bind the company and the user together. Other resources also need to change so that they can best satisfy customer demand. Together they form a community of interest.

The first characteristic of this community of interest is that resources can enter it without any barrier. When you enter it, you must be able to 
create user resources. Second, all partners in this community should be able to get maximized benefit. In the past, the company and its suppliers used to engage in a tug-of-war: I would use whoever offers the least expensive materials. But now, I will use whoever can participate in the initial design process. For example, steelmakers can participate in the initial design process by offering expertise on what kind of steel is best for my product - I have expertise on the product itself but they can offer better solutions when it comes to choosing the right kind of steel. This process maximizes benefit for all. There is a brilliant saying: "Whatever cause it is, if not all participants are benefited, it will not succeed." Even if it did succeed, it would not last long. We have now turned the tug-ofwar into a cooperative relationship. This is not a static relationship as whoever does a good job can join us.

We have a notion: to eliminate the external middleman and the internal "insulated walls." The middleman is useless. The insulated walls are the middle managers. Charles Handy said that the middle managers are cooked geese. They have no sensitivity and are unable to communicate the reality of the market. That's why we downsized by 16,000 people last year. At the beginning of last year, Haier had an 86,000-strong workforce. By year-end, we had 70,000, an 18\% cut. This year we expect to further downsize by 10,000 people. These will be primarily middle managers as well as jobs rendered unnecessary by automation.

\section{Remuneration: Linking Pay to an Individual's Value Creation in a "People-Goal-Pay Combination"}

When both strategy and organization have been reformed, whether you can continue to improve depends on remuneration. How does everyone get paid? In the past, we used the broadbanding system that is popular worldwide. A large global company customized this system for us. But even after the customization, we feel that it has a big problem: in the broadbanding system, everyone gets their pay based on their job or position. In other words, the calculation of pay is based on job and work time. Now we are using a two-dimensional dot chart. The horizontal axis represents the company's value, which are the conventional indicators such as revenue, profit, market share, and so forth. What's important is the vertical axis, which is based on Metcalfe's law about the network value. What is the definition of the network value? The network value is proportional to the size of the network squared.

What is the size of a network? There are primarily two variables: (1) the nodes in the network and (2) the users connected to the network. That's why we are turning every employee in the company into a node in the network. As a node, you need to connect with users in the market. Whoever gets connected with more users can make bigger achievements. In a sense, even if you generate revenue and profit, but are not connected to users, your revenue and profit are not valid. This is a qualitative change. Everyone must be connected with users in the market.

More importantly, I believe the conventional 360-degree evaluation system widely in use by many multinationals where employees are evaluated by their superiors, subordinates, and peers are totally useless here in China. Why? Because in China, we have guanxi. For example, if you tell a co-worker: "I will give you a very good evaluation," then that person will most likely do the same for you. In this way, co-workers collude with each other, rendering the 360-degree useless. We have changed that and now we depend on direct evaluation by users.

We used to have a big, dedicated team that organized 360-degree evaluations. But I felt that was twice the effort for half the result. Now we have users evaluate us. When they say we're good, we are truly good. For example, we promised to give away a product for free if it is not delivered on time. If it is supposed to be at your doorstep by 7pm but arrives after $7 \mathrm{pm}$, it is yours for free. Why pays for it then? Whoever is responsible for the late delivery. Thus, we got the ball rolling. Last year, we delivered more than 780,000 orders. Only 58 orders were given away for free - less than one in 10,000. This system is up and running. Now we are pushing this further: if users click the "like" button on you, you will get a bonus; if they make a complaint about you, you will get criticized.

What are our next steps after strategy, organization, and remuneration? We have three goals: to build a platform-based enterprise, to develop entrepreneurial maker employees, to provide customized user experience.

\section{Building a Platform-Based Enterprise}

What was a company all about in the past? It was all about managing and controlling. Today, the company should become a platform. There are many definitions for the idea of platform. The one that I agree with is that a platform is a framework for fast resource mobilization. When a variety of resources join a platform, it becomes an open ecosystem with its own cycle. To build a platform-based enterprise, we are in fact changing an isolated business into an open ecosystem where you can integrate resources globally to achieve your goal.

\section{Developing Entrepreneurial Maker Employees}

This is a shift from a passive implementer to a self-motivated entrepreneur. This is also a far cry from the past.

\section{Providing Customized User Experience}

In the mobile Internet era, customers are not going shopping; they are shopping all the time. They don't have to go to a shopping mall; they can shop anywhere they want. What's more, an individual customer has now become an individual "center" that publishes their shopping experience in real-time to the entire world. That's why you must be customer-centric. To provide customized user experience is to satisfy the individual needs of each customer.

Lastly, from a philosophical viewpoint, as Immanuel Kant said, people are the ends, not the means to an end. What a brilliant observation. Whoever he or she is, whenever it is, all people, including yourself, must 
not treat all people, including yourself, as means-because people are ends in themselves. On an assembly line, people are treated as means. Now we must treat people as ends.

\section{Paradoxes in the Innovation Process}

Kevin Kelly, a founding editor of Wired magazine, gave us a talk at Haier recently, and I had a discussion with him. He said that in the Internet era, traditional companies are at the peak of hills and they must abandon their old ways, nosedive to the valley, and then climb up the new peak that is the Internet. But I think this is very difficult, if not impossible, to do. Why? Let's take Haier as an example. If we took a nosedive to the bottom of a valley from where we are now with about 30 billion in revenue, we wouldn"t even be able to pay our workers. I cannot afford to wipe out the entire company and start from scratch again. Without going to such length, if I instead just do quick fixes here and there and try to keep the status quo, I wouldn't be able to reach the peak of the Internet. That's why we are now both breaking and building. As we break things, we are also building things so that the structure of the entire company will finally change.

We are hoping to become an ecosystem, as I discussed just before. If I compare each entrepreneurial employee to a tree, many trees form a forest. In this forest, some trees thrive today, some others die tomorrow. In general, the forest is ever-growing. When I was conversing with Provost Price of the University of Pennsylvania, we talked about the differences between Chinese and American companies. I think the biggest difference is that the U.S. has an environment conducive for entrepreneurship whereas China's entrepreneurship environment is problematic. Even in the American environment, some companies survive and some die. I'm hoping that our company will eventually become an ecosystem providing such an environment.

To conclude, I'd like to quote The Book of Changes, a 3100-year-old Chinese book: "Overturning obstruction, instead of being overturned by obstruction. Overturning obstruction: first there is obstruction, afterward joy." Obstruction means being closed and isolated. Overturning obstruction means changing the status of self-isolation and becoming open. Not being overturned by obstruction means to avoid suffocating yourself, as suffocation leads to death. Therefore, the best way is to reinvent yourself. The final result is obstruction first and joy afterwards. At first, the situation is closed and isolated. But with hard work, you will achieve joy and success. I hope all companies in this Internet era will achieve joy after overturning obstruction and succeed in their selfreinvention.

Zhang Ruimin is a world renowned entrepreneur, founder of Haier Group, Secretary of the Party Committee of the Haier Group, Chairman of the Board of Directors and CEO. Zhang Ruimin is the alternative member of the 16th, 17th and 18th Central Committees of the Communist Party of China. Details at http://www.haier.net/en/ about_haier/ceo/introduction/ 